\title{
Psicomotricitat i intel-ligències múltiples. Compartint un espai
}

\author{
Yolanda Cardona Casanova \\ Escola Josep Fusté d'Alforja \\ Universitat Rovira i Virgili \\ yolanda.cardona@urv.cat
}

Resum: Cada cop som més conscients que a les nostres escoles hi tenim diversitat d'alumnat amb diferents necessitats, interessos, capacitats $i$ habilitats. Davant d'aquesta realitat es planteja l'interrogant següent: quines eines, recursos, possibilitats, tenim a l'escola que ens poden ajudar a obtenir informació sobre aquesta pluralitat?

Són moltes les teories que giren al voltant de l'educació, l'ensenyament i l'aprenentatge. La psicomotricitat dinàmica i les intel-ligències múltiples de Gardner han estat les que han ajudat a donar una resposta a l'interrogant que es planteja.

L'experiència que es presenta ha estat realitzada a l'escola Josep Fusté d'Alforja amb el grup d'alumnes de P5.

Lobjectiu d'aquest article és mostrar com dos orígens de treball diferents es poden fusionar per convertir-se en un recurs per observar i planificar la nostra pràctica. El que es pretén és recollir informació que ajudi a entendre les necessitats, interessos, habilitats i capacitats dels infants $i$, a la vegada, ens hi permeti donar resposta.

En tot moment es té present que hi ha més factors que cal tenir en compte a l'hora de decidir què pot ajudar a fer progressar cada infant. Per aquesta raó els resultats de l'observació feta a la sala de psicomotricitat són utilitzats com un complement enriquidor per a la pràctica diària a l'escola.

Paraules clau: Psicomotricitat dinàmica, intelligències múltiples de Gardner, habilitat, interès, observació, coherència educativa.
Abstract: We are increasingly conscious that, in our schools, the student body is diverse with different necessities, interests, capacities and abilities. Facing this reality, we can ask the following question: what tools, resources, possibilities, do we have at school to help us get information about this plurality?

There are many theories around Education, Teaching and Learning. Some help to give an answer to this question can be found in dynamic psychomotor activity and Gardner's multiple intelligences.

It was put into practice at Josep Fusté School (Alforja) with the group of pupils in level P5.

The objective of this article is to show how two different types of work can be fusioned to become a resource to observe and plan our practice. It is meant to gather information to help us understand the necessities, interests, abilities and capacities of the children and, at the same time, to help us answer them.

At all times, it is clear that there are more factors to take into account when deciding what can help each child to improve. That is why the results of the observation in the psychomotor room are used as an enriching complement to the daily practice at school.

Keywords: Dynamic psychomotor activity, Gardner's multiple intelligences, ability interest, observation, educative coherence. 


\section{Introducció}

A la sala de psicomotricitat es dóna l'oportunitat als infants d'actuar a partir d'allò que volen i poden fer. Es parteix de l'infant, a escala individual i en la seva totalitat, per disposar de materials, espais, amb l'objectiu d'acompanyar-lo a partir del diàleg tònic i verbal, de la interacció, del joc amb els companys, del conflicte (social i cognitiu). Això potencia que s'expressi de manera espontània i natural, sempre envoltat d'un ambient assegurador (ordre i normes). En aquest espai són acceptats i compresos tenint en compte les seves característiques individuals, de manera que l’èxit personal està assegurat, la qual cosa fa que l'autoestima i la seguretat siguin uns dels pilars per continuar construint.

En definitiva, estamos hablando de un proyecto de ayuda individualizado para cada alumno/a, que implica acompañarlo a realizar su propio recorrido, partiendo de sus recursos y potencialidades. (Arnáiz, Rabadán, Vives, 2001: 16-17)

Seguint en aquesta línia de treball, H. Gardner (2013: 54-55), en el seu llibre Inteligencias múltiples. La teoría en la práctica, ens diu:

Los encuentros específicamente diseñados con materiales, con equipamiento o con otras personas pueden ayudar a un chico o chica a descubrir su vocación.

[...] De hecho, durante este período prácticamente todos los niños necesitan cierta tutela. Encontrar la forma correcta de ejercer dicha tutela constituye uno de los problemas, puesto que la tutela en grupo puede resultar útil en ciertos casos y perjudicial en otros.

D'aquesta manera es va fer el primer lligam entre la psicomotricitat dinàmica i les intelligències múltiples de Gardner. Els principis metodològics, que formen part dels pilars de la pràctica psicomotriu que presento també formen part dels principis d'acció quan parlem d'intel-ligències múltiples. Totes dues:

- Parteixen de l'infant.

- Parlen d'un acompanyament en els processos d'aprenentatge.

- Donen importància al respecte de les individualitats: interessos, necessitats, habi- litats i capacitats; per tant, a la pluralitat dins del grup-classe.

- Posen èmfasi en la necessitat de crear espais amb materials específics, estimulants i enriquidors.

- Destaquen la riquesa que aporta la interacció amb aquests materials, amb l'igual i amb l'adult.

\section{Contextualització de les dues teories}

A continuació es presenta una breu descripció d'aquells elements que cal tenir presents a l'hora de parlar de psicomotricitat dinàmica i de les intel-ligències múltiples de Gardner. Lobjectiu és ajudar el lector a entendre el contingut de l'article.

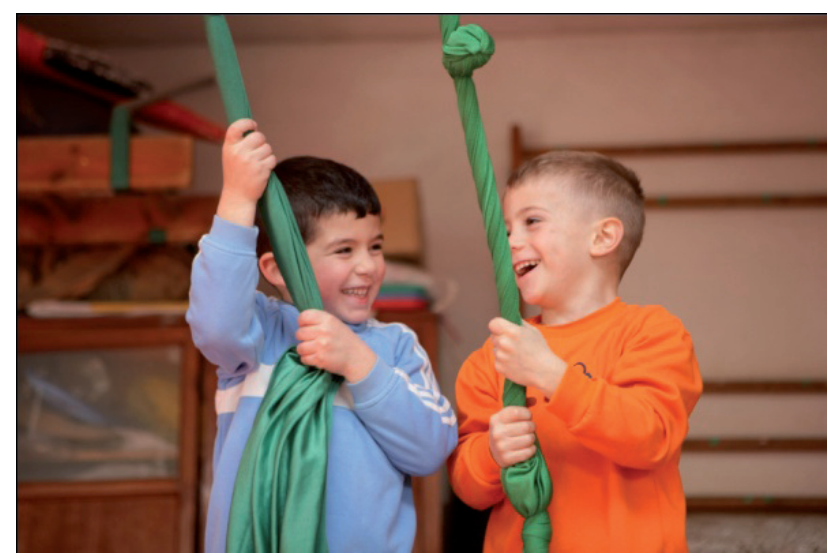

\subsection{Psicomotricitat dinàmica o relacional}

Seguint la línia de treball de B. Aucouturier (2004) i segons ens descriu P. Arnáiz (1988), podem descriure l'acció de l'adult en tres rols:

- Actitud d'escolta vers l'infant a través de l'empatia tònica

L'adult s'ajusta a l'actuació dels nens via corporal i de llenguatge, i dóna resposta a les seves emocions, creativitat, habilitats i interessos. D’aquesta manera s'estableix la comunicació, que està condicionada pels trets i la història personal de cada infant $\mathrm{i}$ de l'adult que hi intervé.

- Símbol d'una llei asseguradora

La llei, en aquesta pràctica, va unida a la seguretat. Durant el joc psicomotor hi ha moltes coses que estan permeses, però aquesta permissivitat només té sentit 
dintre d'un ordre assegurador lligat a unes consignes i accions. D’aquesta manera s’arriba a la confiança: sempre hi ets i amb una mirada neutra, uns criteris coherents i coneguts per ells.

- L'adult com a company simbòlic

Ladult s'incorpora en el joc dels nens no com a jugador, sinó com a acompanyant del joc, amb l'objectiu de fer-lo evolucionar.

El docent actua com a model, com a transmissor d'una sèrie de valors i actituds a partir del "saber estar" en la interacció amb l'infant.

Lligat a "saber fer" hi trobem la metodologia. En aquest treball es té en compte:

- La globalitat

Quan un nen o nena d'aquestes edats actua ho fa posant en joc les seves facultats motrius, emocionals, socials i cognitives a la vegada, sense fragmentar-les.

- La individualitat

Cadascun d'ells creix i aprèn a un ritme diferent i des d'una situació i necessitats específiques. Les habilitats i interessos dels infants són diverses.

- La mirada

És necessari donar una base de comunicació que afavoreixi una relació de respecte. D'aquesta manera, l'infant no se sent jutjat, sent que està davant d'una mirada neutra. Això potencia la seguretat personal que el porta cap al desenvolupament de les seves capacitats, habilitat i interessos.

- Ladaptació

A mesura que els nens van madurant, la intervenció de l'adult evoluciona amb ells. Sadapta a allò que va canviant.

Tot aquest plantejament es materialitza dins la sala de psicomotricitat durant el desenvolupament de les sessions. Per parlar de la seva estructura, ens basem en el treball de B. Aucouturier (1985) i P. Arnáiz, M. Rabadán i I. Vives (2001):

\section{- Ritual d'entrada}

- Entrar en calma i sense sabates.

- Estona de diàleg: acolliment, presentació dels racons de joc, es donen les consignes, es recorda quin és el desenvolupament de la sessió i les normes.

- Fase de l'expressivitat motriu

Centrat en el cos i les emocions. Lespai de la sala sorganitza per potenciar tres tipus d'activitats:

- Jocs de "seguretat profunda", pulsió inicial:

És el moment del trencament inicial i de l'aparició del plaer. S'aconsegueix mitjançant torres de coixins/peces d'espuma/caixes de cartró, un matalàs vertical, una guerra de pilotes, un llençol de paper de diari, etc. Aquesta acció permet a l'infant vivenciar un primer moment de destrucció, d'equilibri i desequilibri, de jocs d’oposició i de desestructuració de l'espai. Lactivitat en aquest moment està lligada a la pulsió de descàrregues emocionals, en treure tensions corporals i, d'aquesta manera, afavorir la interacció amb l'igual i l'adult.

- Joc sensoriomotor:

En un espai ben assegurat, els nens saltaran, pujaran, cauran, jugaran amb l'equilibri vivenciant $i$ interioritzant diferents sensacions i ajustos tònics que els faran viure situacions de plaer i desplaer, de fragmentació i totalitat, entre d'altres. Aquestes experiències són les que els portaran cap a la presa de consciència del propi cos i de les seves possibilitats de moviment.

- Joc simbòlic:

L'infant, mitjançant el joc simbòlic, posa de manifest el seu jo més profund, el qual és mirat i acceptat per l'adult. En aquest moment, allò que ens mostra fa referència a fets que els nens han viscut i han sentit. Aquest moment desperta tot un procés doperacions cognitives i reforça la seva identitat.

- Tornada a la calma

- Descans i relaxació:

Es produeix el distanciament de l'acció. Durant aquesta estona el cos dei- 
xa d'actuar per descansar. La musculatura es relaxa, el silenci ocupa l'espai, una música suau i relaxada pot acompanyar aquest moment, la presa de consciència de la totalitat arriba fent rodar una pilota per damunt del cos, tapant el cos amb un llençol, etc.

- Fase de l'expressivitat verbal, gràfica $o$ plàstica:

Centrat en el treball cognitiu i lògic. Lespai de la sala es destina a activitats de representació. L'infant té la possibilitat d'evocar mitjançant el llenguatge verbal, el dibuix, el modelatge o les construccions allò que ha viscut durant la sessió.

\section{- Ritual de sortida}

- Comiat.

- Posar-se les sabates.

Amb tot, l'infant es mou dins d'un context d'interacció amb els materials, l'igual i l'adult que el porta a saber resoldre conflictes socials i cognitius. El porta a sentir i a emocionar-se fent que allò vivenciat perduri en la memòria i l'encamini cap a l'aprenentatge significatiu.

\subsection{Les intel-ligències múltiples}

Gardner (2013: 27) defineix la intel-ligència com:

la capacidad para resolver problemas, o para elaborar productos que son de gran valor para un determinado contexto comunitario o cultural.

Per a ell l'escola ha de tenir en compte que:

- No tots els nens tenen els mateixos interessos ni capacitats: "no todos aprendemos de la misma manera" (Gardner, 2013: 30).

- No podem pretendre que s'aprengui tot: "nadie puede llegar a aprender todo lo que hay que aprender" (Gardner, 2013: 31).

Partint d'aquest plantejament, Gardner (2013) fa referència a diferents professionals:

- "Especialistas evaluadores"

La seva funció és descobrir les habilitats i interessos dels nens. Marca la importància de fer ús d'instruments neutres respecte a les intel-ligències i de les possibilitats d'ob- servació a partir d'una mirada sense condicions ni condicionants.

- "Gestor"

Ladult és qui s'encarrega de determinar què afavoreix el desenvolupament i aprenentatge de cada infant.

- "Gestor escuela-comunidad"

El paper d'aquest professional és establir lligams entre l'escola i la societat $i$, a partir d'aquests lligams, trobar situacions enriquidores per als infants que no troben resposta dins les aules.

- "Maestros"

Són els que ensenyen i s'adapten a les diferents realitats de l'aula.

- "Coordinadores"

Aquests tenen la tasca de coordinar i supervisar el treball de la resta de professionals que hi intervenen, amb l'objectiu de lligar els processos d'ensenyament i aprenentatge.

Aquesta teoria aplicada al context de l'escola actual es pot traduir a dur a terme diferents metodologies de treball, activitats diverses, fer ús de diferents espais, materials i recursos respectant d'aquesta manera l'àmbit més competent dels nostres alumnes.

Continuant en l'enfocament que ens fa Gardner (2013) sobre les intel-ligències múltiples, parlem de diferents tipus d'intel-ligències:

- Intel-ligència intrapersonal

És la capacitat de crear una imatge equilibrada i verídica d'un mateix a partir de conèixer, comprendre i acceptar allò que forma part de nosaltres, i ser capaç de fer-ne ús per saber ser i estar a la vida.

- Intel-ligència interpersonal

Parlem de la capacitat d'entendre els altres. Facilita el treball en grup, ja que és capaç de comprendre allò que l'altre comunica: intencions, aportacions, interessos i necessitats.

- Intel-ligència corporal-cinestèsica Es dóna quan es té la capacitat d'utilitzar el cos per donar resposta a les dinàmiques del dia a dia i per enfocar el resultat del treball propi. 
- Intel-ligència musical

Molt lligada a la música quant a la capacitat per interpretar, compondre i aprendre tot allò relacionat amb aquest art.

- Intel-ligència espacial

Fa referència a la capacitat de crear una imatge mental de l'espai real i utilitzar-la com a eina per desenvolupar activitats.

- Intel-ligència lingüistica

Es fa ús del llenguatge per arribar a allò que es vol assolir. En l'àmbit d'expressió verbal i escrita es té molta capacitat de creació i producció. Els idiomes formen part de les seves habilitats i interessos.

- Intel-ligència logicomatemàtica

Ens mostra la capacitat de resoldre els problemes de manera lògica i de realitzar investigacions de manera científica.

- Intel-ligència naturalista

Incorporada recentment. Inclou aquells perfils que tenen facilitat per entrar en contacte amb l'entorn natural i els éssers vius. Mostren tenir habilitat a l'hora d'organitzar, classificar i ordenar diferents tipus d'elements amb lobjectiu d'obtenir un resultat.

\section{Connexió entre les dues teories}

A l'hora de plantejar-nos els processos metodològics de treball, cal reflexionar sobre les possibilitats de la pràctica psicomotriu dinàmica vers el desenvolupament de les habilitats, capacitats i estratègies d'aprenentatge individuals que afavoreixen dinàmiques de treball promotores dels plantejaments transmesos en la teoria d'intelligències múltiples de Gardner.

Seguidament es presenta com es respecten els diferents tipus d'intel-ligències múltiples de Gardner dins la pràctica psicomotriu dinàmica i com ens donen informació sobre com poder treballar amb els infants dins de l'àmbit escolar.

- Intel-ligència intrapersonal

A la sala de psicomotricitat es potencia que explorin les possibilitats pròpies, que desenvolupin habilitats partint de les seves capacitats, sense por de ser jutjats. Hi ha un adult que els accepta tal com són, els anima i els ajuda amb l'objectiu de fer-los sentir cada cop més segurs.
D'AQUESTA MANERA L'INFANT SE SENT RECONEGUT I AIXÒ LI DÓNA SEGURETAT AFECTIVA I EMOCIONAL = POTENCIACIÓ DE L'AUTOESTIMA.

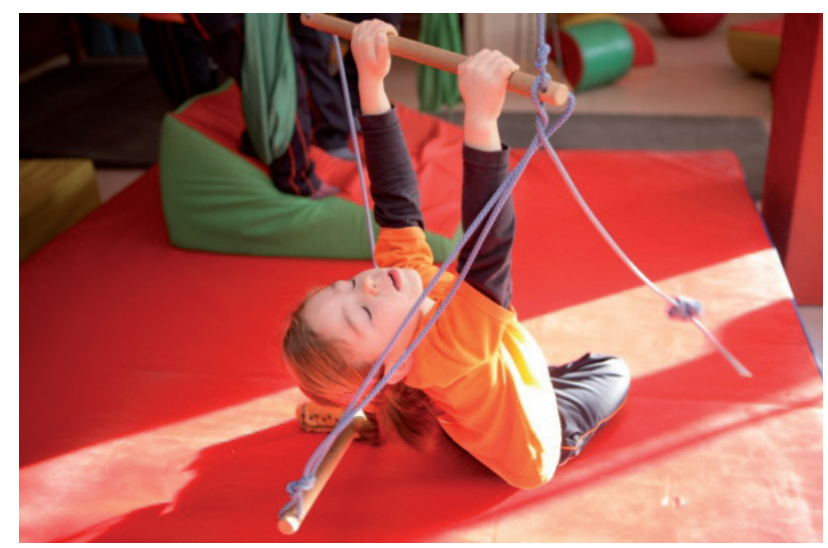

Es potencia el control del propi cos a partir de les habilitats que té cada nen o nena. Se'ls estira a partir del que poden fer. Així es va aconseguint, a poc a poc, el control del propi cos (s'adona que fa progressos).

\section{D'AQUESTA MANERA CREA UNA IMATGE POSITIVA D’ELL/A MATEIX/A.}

Aquí trobem reflectida la intel-ligència intrapersonal. Posant la mirada en nens de 3 a 6 anys, s'inicia amb el coneixement i acceptació d'habilitats, capacitats i limitacions de manera sana i natural. Sense angoixes, vergonyes, neguits, pors ni infravaloracions.

Això en un futur pot encaminar l'infant a tenir la capacitat de comprendre's i acceptar-se a si mateix.

- Intel-ligència interpersonal

Durant les sessions també es fomenta la interacció entre iguals. El fet de compartir un espai li permet establir relacions dins d'un marc de llibertat d'acció tenint en compte unes normes de convivència que cal respectar. És un espai que dóna peu al fet que sorgeixi el conflicte social. Sol aparèixer a l'hora de compartir un material, un moment i un espai.

La resolució de conflictes de manera respectuosa i equilibrada fa que l'infant s'acostumi a veure i a tenir present l'altre a l'hora de prendre iniciatives i dur a terme les seves accions. 
D'AQUESTA MANERA L'INFANT APRÈN A AUTOREGULAR-SE, S'ADONA QUE HI HA DIFERENTS PUNTS DE VISTA I DIFERĖNCIES INDIVIDUALS QUE HAN DE SER RESPECTATS.

Ara podem parlar d'intel-ligència interpersonal. Aquest aprendre a respectar l'altre i a tenir-lo en compte, en un futur podrà manifestar-se com a empatia, una actitud d'escolta i respecte. Aquests trets són els que afavoreixen el treball en equip, el treball cooperatiu, etc.

- Intel-ligència corporal-cinestèsica

Es fa ús de l'activitat motriu espontània perquè és la que permet als nens expressar el seu moviment (motriu, simbòlic i expressiu) lliurement. Ladult no proposa el joc, disposa el material de manera que pugui generar moviment, joc motriu, interacció, etc. Ladult, en tot cas, s'incorpora en el joc creat pels infants acompanyant els nens simbòlicament $\mathrm{i}$ està disponible, amb una actitud d'escolta per donar resposta a les seves demandes i necessitats.

\section{D'AQUESTA MANERA L'ACTIVITAT DE L'INFANT EVOLUCIONA FENT QUE SIGUI MÉS AUTÒNOM EN L'ÀMBIT MOTRIU I EXPRESSIU.}

Aquest plantejament portat a l'àmbit de les intel.ligències múltiples de Gardner ens permet parlar de la capacitat d'utilitzar el cos (en la seva totalitat o parcialment) per crear i adquirir habilitats que ajudin en el desenvolupament i la integració d'aprenentatges per a la vida, tant la de l'infant com la de l'adult. Mitjançant el cos i el moviment, fa ús del llenguatge no verbal. Una comunicació corporal i gestual que sovint dóna més informació que la verbal. Cal tenir en compte que és el primer llenguatge de l’infant i un dels pilars de la comunicació.

- Intel-ligència musical

En diferents moments de la sessió de psicomotricitat, la música acompanya el moviment, el llenguatge/expressió corporal i el to muscular:

- Quan els nens entren a la sala, els espera una música tranquil.la i acollidora que els acompanya durant l'estona que es posen els mitjons antilliscants i esperen que tothom estigui preparat per escoltar com s'ha disposat la sala per jugar.

- Cada sessió s'inicia amb música, mitjançant la qual els nens mouen el cos lliurement seguint el ritme d'una música, d'uns ritmes marcats per un pandero, pandereta, etc.

- Una altra música marca el moment de recollir i preparar-nos per passar del moviment a la calma.

- Per acabar, una música relaxant fa que els nens busquin un espai per estirar-se, tapar-se, fer un massatge i descansar.

D'altra banda, hi ha sessions on es disposa d'un racó amb material musical de percussió. Els nens poden experimentar-hi.

D'AQUESTA MANERA L'INFANT VIVENCIA LA MÚSICA EXPERIMENTANT, IMPROVISANT, JUGANT AMB EL SEU COS I ELS PROPIS MOVIMENTS, INTERACCIONANT AMB ELS ALTRES I AMB ELS OBJECTES.TOT AIXÒ LI PERMET CREAR I DONAR A CONĖIXER ELS SEUS INTERESSOS, HABILITATS I CAPACITATS. S'ADONA QUE ELS MOVIMENTS RÍTMICS I ELS SONS EMESOS L'AJUDEN A EXPRESSAR-SE.

Posant la mirada en les intel-ligències múltiples, aquest àmbit psicomotriu pot ajudar l'infant a descobrir les seves habilitats musicals i despertar la seva capacitat d'interpretar, crear i aprendre pautes musicals. La música es pot convertir en un instrument o eina d'expressió, un llenguatge més.

- Intel-ligència espacial

Es presenta una pràctica psicomotriu que permet als nens construir/destruir, muntar/desmuntar, crear/corregir, afegir/treure, a partir de materials durs i tous, grans i petits, amb color i sense. Amb això els nens poden i són capaços d'introduir-se en el joc simbòlic, joc que afavoreix la creació i representació en l'espai de construccions en tres dimensions. La dinàmica de les sessions potencia el desenvolupament de la capacitat representativa i simbòlica dins d'un espai. 
Allò que creen ocupa un espai dins la sala. Ells organitzen els materials tenint en compte aquest espai i l'espai real del seu joc.

Com he assenyalat anteriorment, al final de cada sessió es fa la representació d'allò que s'ha fet en l'àmbit verbal, mitjançant el dibuix o el volum (fang, plastilina o fustes). Aquesta representació fa que els nens materialitzin una realitat viscuda en un espai diferent d'on s'ha fet la vivència. Durant aquest moment, se li demana que concreti allò que ha experimentat dins d'un marc limitat (paper o espai per a la construcció o modelatge) Aquesta és una altra manera de vivenciar l'espai: representant-lo tenint en compte uns límits.

L'espai de la sala de psicomotricitat no és únicament un lloc físic i amb materials; també és un espai carregat de moviment i emocions, on es poden expressar tal com són, un lloc de plaer, de descobriments i d'interacció.

Aquesta interacció potencia la manipulació, experimentació, descobriment, verbalització, principis metodològics bàsics de l'aprenentatge per descobriment i necessari si el que volem és afavorir l'aprenentatge significatiu i funcional en els infants.

La vivenciació de l'espai i del temps a partir del propi cos fa que els nens interioritzin la seqüència temporal d'esdeveniments en diferents moments de la sessió i espais de la sala.

Els nens estructuren el pas del temps d'acord amb la seqüència d'accions que duen a terme en l'espai. Així, doncs, ells saben que al principi hi ha una estona de diàleg, seguida d'un moment curt per a la pulsió, que després hi ha una estona de joc sensoriomotriu i simbòlic, s'adonen que l'estona de joc dinàmic és la més llarga i que quan s'apaga el llum i sona la música és l'hora de la relaxació.

D'AQUESTA MANERA L'INFANT POT ESTABLIR RELACIONS ENTRE ELS OBJECTES A PARTIR DE L'ASSAIG-ERROR I ELABORAR UNA PRIMERA REPRESENTACIÓ MENTAL DE L'ESPAI I EL TEMPS.

En l'àmbit de les intel-ligències múltiples, la psicomotricitat pot ajudar l'infant a descobrir la capacitat de manipular, reconèixer i identificar diferents espais a partir de la vivència/interacció d'un mateix amb els altres i amb diferents materials. Aquesta interacció permet prendre consciència de distàncies, volums, mides, etc. Elements que ajuden a representar espais quan ja no són presents.

- Intel-ligència lingüística

Es fa ús del llenguatge verbal a l'inici de la sessió, durant l'estona de joc i també al final de la sessió. És en aquest darrer moment quan es fa que posin paraules a les seves vivències.

Durant l'estona de joc els nens expressen verbalment les seves necessitats i els seus interessos als companys i a l'adult. El llenguatge serveix per mostrar-se als altres, expressar emocions i, mitjançant la pràctica, adquireixen estratègies de comunicació. Durant l'estona de calma es potencia que els nens representin mitjançant el dibuix, les paraules, el modelatge i les construccions les pròpies vivències dins la sala (explicat en l'apartat anterior).

Es fa ús del llenguatge per recordar i fer present una activitat passada. Això ajuda l'infant a estructurar el pensament. Dóna a conèixer el que interioritza com a aprenentatge.

D'AQUESTA MANERA ES POTENCIA L'APRENENTATGE DE FORMES D'EXPRESSIÓ MÉS ELABORADES QUE AJUDEN QUE L'INFANT ASSOLEIXI EL LLENGUATGE VERBAL I GRÀFIC.

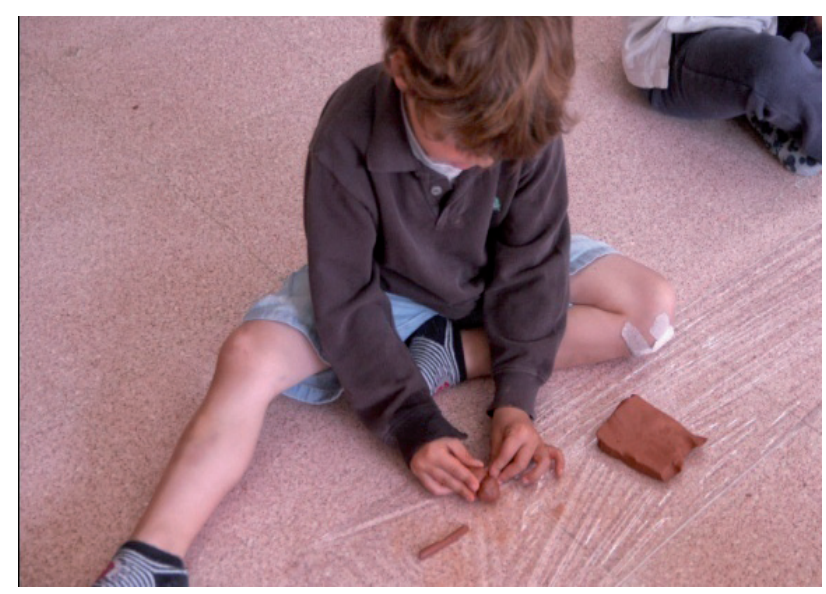

D’aquesta manera, en l'àmbit de les intelligències múltiples de Gardner, podem dir que en context escolar els nens aprenen/comencen a utilitzar el llenguatge per aconseguir objectius 
personals, de grup, d'aprenentatge, de convivència, etc. Es fa ús del llenguatge i la representació com a eina d'expressió. Cal assenyalar que estem posant la mirada en infants, sense perdre de vista que aquests són els que constituiran la societat del futur.

- Intel-ligència logicomatemàtica

Sovint els nens han de resoldre conflictes cognitius utilitzant criteris lògics, aplicant la lògica matemàtica, estratègies de càlcul, assaig-error, experimentació a partir de la manipulació i el tanteig.

Fer una construcció amb peces dins d'un determinat espai implica el càlcul de les mides de les peces que utilitzarà, el fet de voler fer arribar una pilota a un lloc determinat mentre ha de passar per determinats plans horitzontals, inclinats $\mathrm{i}$ rugosos implica mesurar les forces. Aquests són només dos exemples de la quantitat de situacions en què els nens han de crear estratègies lògiques per assolir el seu propòsit.

La sala de psicomotricitat és un espai que permet a l'infant experimentar i vivenciar conflictes cognitius als quals ha de donar com a resposta una solució logicomatemàtica. A més a més, és un espai on pot compartir dubtes amb els seus iguals i amb ells trobar solucions de manera activa.

Crear hipòtesis sobre el resultat de les seves accions, provar-ho, fer-ho d'una altra manera quan no surti, observar els companys i intentar trobar una solució comuna són dinàmiques presents en totes les sessions.

\section{AIXÍ, L'INFANT APRÈN A ARRIBAR A DETERMINATS APRENENTATGES A PARTIR DE CONFLICTES COG- NITIUS. DURANT EL PROCÉS, APRÈN A TROBAR SOLUCIONS MITJANÇANT PROCESSOS LÒGICS A PARTIR DE LA CREACIÓ D'HIPÒTESIS, L'EXPE- RIMENTACIÓ, L'ASSAIG-ERROR, EL CONTRAST DE RESULTATS I, FINALMENT, LA VERIFICACIÓ D’ALLÒ QUE HA ESTAT EXPERIMENTANT.}

El que apareix en l'àmbit de les intel-ligències múltiples com a capacitat d'analitzar problemes d'una manera lògica, de solucionar problemes matemàtics i realitzar investigacions d'una manera científica, a la sala es posa de manifest mitjançant els conflictes cognitius per acabar aconseguint un objectiu: construir una casa, un vaixell, un avió, fer pujar una pilota per un pla inclinat i que caigui dins d'una caixa, posar unes totxanes de plàstic dins d'un caixó, construir una xarranca amb cercles, fer una torre alta sense que caigui, etc.

- Intel-ligència naturalista

Cal assenyalar que, durant el desenvolupament de les sessions, es fa ús d'un vocabulari tècnic que ajuda els infants a identificar el material, a agrupar-lo i a classificar-lo a l'hora de jugar i de recollir. Així, doncs, gran part dels nens, quan acaben l'educació infantil, saben que quan parlem de:

- Material dur: fem referència al pla inclinat, cercles, totxanes, bancs, bastons, etc.

- Material tou: parlem de les peces de construccions, pilotes de salt, pilotes toves, matalassos, etc.

- Material d'equilibri: ho relacionen amb les alces, barra d'equilibri, peces cilíndriques, etc.

- Material de joc simbòlic: saben que són les robes, peces, etc.

D'altra banda, cal assenyalar que hi ha sessions en què els materials són caixes de cartró, a partir de les quals els nens hi interaccionen ordenant-les per mides, fent torres encaixant-les, classificant-les per mides, formes i colors.

ESCOLTANT I EXPERIMENTANT ELS NENS APRENEN A UTILITZAR EL MATERIAL A PARTIR DE LES QUALITATS QUE EL DETERMINEN. AIXÒ DÓNA PEU A CREAR ESTRATÈGIES DE PENSAMENT QUE POTENCIEN LA CLASSIFICACIÓ DE MATERIALS I LA DIFERENCIACIÓ ATESES LES POSSIBILITATS DE JOC QUE AQUESTS MATERIALS ELS PROPORCIONEN.

Aquest plantejament des de la mirada de les intel-ligències múltiples complementa l'aprenentatge d'aquells nens amb un pensament que requereix metodologies que contemplin el treball per agrupaments, classificacions, etc. D'aquesta manera, se'ls ajuda a interioritzar allò que se'ls vol fer arribar com a base de futurs aprenentatges. 


\section{Psicomotricitat dinàmica $\mathrm{i}$ intel-ligències múltiples de Gardner: la pràctica}

Després d'haver fet aquesta reflexió buscant allò que la psicomotricitat pot aportar en el treball de les intel-ligències múltiples, s'ha passat a l'acció.

La pràctica que es presenta consisteix a planificar i programar diferents sessions de psicomotricitat tenint en compte les vuit intel-ligències múltiples.

Per fer-ho es va pensar en racons de joc i dinàmiques que donessin peu al fet que els nens poguessin manifestar les seves prioritats de joc (interessos) i allò que els és innat com a persones (habilitats). D'aquesta manera, a l'inici de les sessions, durant l'estona de diàleg, es tenen en compte consignes com aquestes:

- En l'espai d'equilibri pot ser que necessitem ajuda per passar. Qui necessiti que l'acompanyin ho pot demanar a un amic $o$ amiga $o$ a la senyoreta (intel-ligència intrapersonal). Si algú veu que un amic o amiga necessita ajuda per passar el podem anar a acompanyar (intel-ligència interpersonal).

- Avui tenim un racó on ens podem tapar els ulls. Amb els ulls tapats podem passejar per la sala. La resta hem de vigilar que no es faci mal. Així que si veiem un amic $o$ amiga que necessita que l'acompanyem, què farem? (Intel-ligència interpersonal).

- Com podeu veure, avui hem penjat la barra de trapezi, les teles i el gronxador. A veure qui descobreix el que s'hi pot fer? (Intel-ligència corporal-cinestèsica).

- Primer xerrarem una estoneta sobre tot allò que podem fer avui a la sala i després despertarem el cos amb música (intelligència musical).

- Avui voleu construir alguna cosa? Algú recorda si va fer una construcció la setmana passada? Què vau construir? (Intelligència espacial).

- Després de descansar, què farem? Que mexplicareu el que us ha agradat més fer avui a la sala? Fareu un dibuix i després m'ho explicareu, d'acord? (Intel-ligència lingüística).
- Si us hi fixeu, hi ha un racó amb pilotes on podeu construir rampes i aprofitar el tobogan. Quines pilotes baixaran més ràpid? Per quina rampa baixaran millor? (Intel-ligència logicomatemàtica).

- Amb les caixes de cartró, què podem fer? (Intel-ligència naturalista).

Durant el final del primer trimestre i l'inici del segon es va fer l'observació dels infants dins la sala de psicomotricitat tenint en compte els paràmetres següents:

- Els racons/espais de joc motriu on interactua.

- La capacitat de comunicar.

- Les habilitats per resoldre conflictes socials.

- La tolerància a la frustració.

- La seva actitud, tenint en compte la capacitat de gaudir d’allò que experimenten i produeixen a la sala.

A partir d'una taula d'observació es van anar recollint diferents informacions amb l'objectiu de poder-les transformar en dades complementàries a la resta de valoracions que tenim sobre el grup classe. L'observació ha estat enfocada com un mitjà per recollir allò que ens apropa a la comprensió i a conèixer una mica millor els infants.

D’altra banda, també s'ha fet ús de la càmera de fotos per contrastar, a partir de les imatges, la informació recollida a les taules.

Es parteix d'una concepció del psicomotricista com aquell que cerca, reflexiona i valora. La seva activitat en aquest moment se centra en l'observació sistemàtica i l'anotació de dades. Es tracta de recollir les informacions que serveixen per interpretar cada un dels processos motrius, emocionals, socials i cognitius que tenen lloc a la sala de psicomotricitat.

\section{Després de l'experiència... què podem dir-hi?}

Amb aquest treball he intentat fer una reflexió a partir d'una pràctica habitual (PD) amb els nens i una dinàmica recentment coneguda per mi (IMG). D'aquesta manera ha aparegut la possibilitat d'enriquir la pràctica a la sala de psicomotri- 
citat introduint una nova mirada que ens porta a veure una mica més de cada infant.

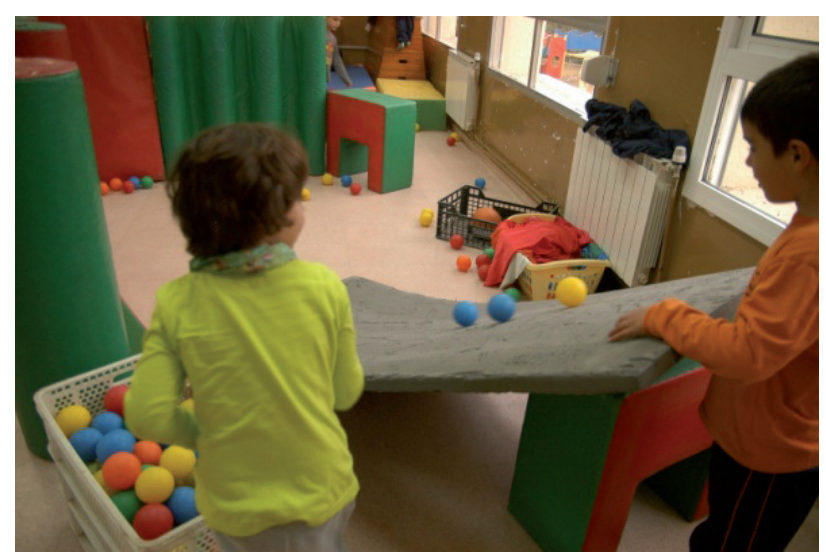

Sovint com a professionals ens plantegem interrogants i necessitem conèixer altres maneres de fer que puguin enriquir el nostre dia a dia a les aules.

Des de la meva escola ens adonem que ensenyar implica posar diferents mirades a un mateix procés. Per aquesta raó, la formació i el diàleg per trobar respostes forma part del nostre treball.

L'experiència presentada, tot i que no fa que els nens prenguin consciència directa que hi ha diferents tipus d'intel-ligències ni que s'identifiquin amb una d'elles, sí que ens permet crear una dinàmica d'aprenentatge on cadascú pot buscar el lloc, el camí, la manera d'aprendre a partir d'allò que li ha despertat interès i d'allò en què és hàbil. La sala de psicomotricitat dóna aquesta possibilitat a causa del lligam que existeix entre la filosofia de treball de les dues dinàmiques plantejades: psicomotricitat dinàmica i intel-ligències múltiples de Gardner.

Per acabar, m'agradaria agrair als meus companys i companyes el respecte vers el treball psicomotriu que es fa a l'escola i a les famílies i nens i nenes de P5 la seva col-laboració.

\section{Bibliografia}

Aucouturier, B. (2004). Los fantasmas de acción y la práctica psicomotriz. Barcelona: Graó. Aucouturier, B.; Darrault, I.; Empinet, J. L. (1985). La práctica psicomotriz, reeducación y terapia. Barcelona: Científico-Médica.

Arnáiz, P. (1988). Fundamentación de la práctica psicomotriz en B. Aucouturier. Madrid: Seco Olea Ediciones.

Arnáiz, P.; Rabadán, M.; Vives, I. (2001). La psicomotricidad en la escuela: una práctica preventiva y educativa. Màlaga: Ediciones Aljibe.

GARdNer, H. (2013). Inteligencias múltiples. La teoría en la práctica. Madrid: Paidós.

\section{Curs}

Cano, M. (2014). "Les Intel-ligències Múltiples: de la Teoria a la Pràctica". Reus: Fundació URV. 